OPEN ACCESS

Edited by: Gaetano Santulli, Columbia University, United States

Reviewed by: Enzo Spisni, University of Bologna, Italy Joel Friedman, Albert Einstein College of Medicine United States

Burtram Clinton Fielding, University of the Western Cape, South Africa

*Correspondence: Savneet Kaur savykaur@gmail.com

Specialty section

This article was submitted to Clinical and Translational Physiology, a section of the journal Frontiers in Physiology

Received: 07 May 2020

Accepted: 20 July 2020 Published: 04 August 2020

Citation:

Kaur S, Tripathi DM and Yadav A (2020) The Enigma of Endothelium in COVID-19. Front. Physiol. 11:989.

doi: 10.3389/fphys.2020.00989

\section{The Enigma of Endothelium in COVID-19}

\author{
Savneet Kaur ${ }^{1 *}$, Dinesh M. Tripathi ${ }^{1}$ and Angeera Yadav ${ }^{2}$ \\ ' Department of Molecular and Cellular Medicine, Institute of Liver and Biliary Sciences, New Delhi, India, ${ }^{2}$ Department of \\ Pharmacy Practice, National Institute of Pharmaceutical Education and Research, Guwahati, India
}

Coronavirus disease 2019 (COVID-19), caused by severe acute respiratory syndromerelated coronavirus-2 (SARS-CoV-2) has affected millions of people globally. Clinically, it presents with mild flu-like symptoms in most cases but can cause respiratory failure in high risk population. With the aim of unearthing newer treatments, scientists all over the globe are striving hard to comprehend the underlying mechanisms of COVID-19. Several studies till date have indicated a dysregulated host immune response as the major cause of COVID-19 induced mortality. In this Perspective, we propose a key role of endothelium, particularly pulmonary endothelium in the pathogenesis of COVID-19. We draw parallels and divergences between COVID-19-induced respiratory distress and bacterial sepsis-induced lung injury and recommend the road ahead with respect to identification of endothelium-based biomarkers and plausible treatments for COVID-19.

Keywords: COVID-19, endothelial dysfunction, pathogenesis and diagnosis, viral sepsis, inflammation, coagulation, vascular biology

\section{INTRODUCTION}

Endothelium is a highly specialized and dynamic organ which serves numerous roles in both physiology and pathophysiology (Galley and Webster, 2004). Being the first organ to perceive any damage to the underlying tissue, it effectively adapts and mounts compensatory responses to any chemical, mechanical and cellular injury. The pulmonary endothelium that shields the lungs comprises of both macro or microvascular endothelial cells with considerable phenotypic and functional heterogeneity (Aird, 2007). Pulmonary microvascular endothelial cells (mEC) are an integral part of the alveolar (epithelial)-capillary (endothelial) barrier formed by tight junctions and adherens junctions in the lungs. This impermeable alveolar-capillary barrier strictly restricts vascular fluid fluxes across the lung epithelium and hence the integrity of this barrier is utmost to prevent pulmonary edema, congestion and respiratory failure (Millar et al., 2016). In the current perspective, we envisage a key role of $\mathrm{mEC}$ in the pathogenesis of coronavirus disease 2019 (COVID-19) caused by the novel coronavirus, severe acute respiratory syndrome-related coronavirus-2 (SARS-CoV2).

\section{COVID-19 AND PULMONARY INFLAMMATION}

COVID-19 has a wide clinical spectrum ranging from asymptomatic to mildly symptomatic forms to severe clinical conditions such as respiratory failure, sepsis and multiorgan dysfunction syndromes (MODS) (Yang X. et al., 2020). Most of the hospitalized critically ill COVID-19 patients have pneumonia with abnormal chest CT scans and acute respiratory distress syndrome 
(ARDS) seems to be the major causes of death in these patients (Yang F. et al., 2020). ARDS is nothing but a reflection of severe $\mathrm{mEC}$ dysfunction involving changes in vascular permeability, inflammation, accumulation and extravasation of leucocytes, activation of procoagulant pathways and disruption of alveolarcapillary barrier (Matthay et al., 2019). Evidence from several studies have indicated that patients with COVID-19 exhibit most of these attributes. Lung pathology from COVID-19 patients has depicted that along with pulmonary type 2 alveolar epithelial cells, endothelial cells in the systemic venules are also desquamated and an inflammatory reaction is present in blood vessel walls (vasculitis), suggestive of intense vascular reactions (Ding et al., 2003). Lung autopsies from COVID-19 patients also show massive neutrophil infiltration in pulmonary capillaries, acute capillaritis and extravasation of neutrophils into the alveolar space (Fox et al., 2020; Liu et al., 2020). Pulmonary neutrophilia is predictive of poor clinical outcomes and also neutrophil-to-lymphocyte ratio is an independent risk factor of disease severity in these patients (Liu et al., 2020). An inflamed/injured endothelium due to increased expression of adhesion molecules, including E- and P-selectins, loss of cadherin junctions and hence altered vascular permeability promotes the adhesion and migration of neutrophils. Neutrophilia can induce injury to the endothelium-epithelial alveolar barrier, causing further damage to the lungs. A recent report has illustrated that neutrophil extracellular traps (NETs) are enhanced in hospitalized COVID-19 patients receiving mechanical ventilation as compared with hospitalized patients breathing room air. The study has also documented that sera from individuals with COVID-19 trigger NET release from control neutrophils in vitro (Zuo et al., 2020). NETs are extracellular DNA fibers of neutrophils carrying nuclear proteins, such as histones and bactericidal proteins. NET formation in the lungs is documented in bacterial sepsis and thrombosis, however, their role in viral infections is not very well known except for a report which has shown their presence in influenza virusinduced pneumonia in vivo (Narasaraju et al., 2011). NETs represent one of the powerful host mechanisms to damage the microbes. They are, however, suicidal, if present in excess as they can attach to the capillary endothelium, collate with the platelets to induce coagulation and thus cause damage to the alveolar-capillary barrier, leading to vascular leakage, edema and finally ARDS (Sørensen and Borregaard, 2016). Ascertaining the role of NETs as markers of COVID-19 disease severity needs further systematic studies and targeting of NETs to rescue the lung endothelium represents a worthwhile therapeutic option in COVID-19.

\section{COVID-19-INDUCED ATYPICAL ARDS}

Several studies have indicated the presence of atypical manifestations of ARDS in some severe patients of COVID19. They exhibit near normal pulmonary compliance of $>50 \mathrm{ml} / \mathrm{cmH}_{2} \mathrm{O}$ with severe hypoxemia, which seems to emanate due to impaired hypoxic pulmonary vasoconstriction (HPV) and ventilation/perfusion (V/Q) mismatch (Gattinoni et al., 2020).
An impaired HPV in these patients point toward mEC dysfunction in the lungs as recent studies have postulated that the alveolar ion channels in the endothelial cells of the alveolarcapillary barrier are sensors of oxygen/hypoxia that propagate the messages along the vascular endothelium and initiate arteriolar vasoconstriction or HPV (Grimmer and Kuebler, 2017). These patients show features of vasoplegia or persistent hypotension as observed in sepsis patients with atypical ARDS, indicative of a primary insult to the pulmonary endothelium (Gattinoni et al., 2020). Lung histology in COVID-19 patients with severe respiratory failure also indicates that COVID-19 has features distinct from typical ARDS (Klok et al., 2020). The pulmonary abnormalities in these patients comprise of thrombotic microvascular injury in the alveolar capillaries, with fewer signs of viral cytopathic or fibroproliferative changes. Pulmonary thromboembolic complications with a distinct pro-coagulant profile, elevated $\mathrm{D}$-dimer levels and angiogenesis is a common finding in many severe cases of COVID-19 patients (Ackermann et al., 2020; Ranucci et al., 2020). Increased ratio of angiogenic factor, soluble fms-like tyrosine kinase 1 (sFlt-1)/PLGF (placental growth factor) ratio in COVID-19 positive patients as compared to patients with COVID-19 negative pneumonia, and healthy donors is recently documented (Giardini et al., 2020). The use of the s-Flt1/PlGF ratio in COVID-19 as a clinical tool to stratify the intensity of endothelial dysfunction has been proposed in this study.

A healthy lung endothelium has an inhibitory effect on inflammation and coagulation while a procoagulant phenotype is a hallmark of an injured endothelium in sepsis and ARDS both (Millar et al., 2016). These studies along with the fact that the pulmonary epithelium is more resistant to injury than the endothelium signify that SARS-CoV-2-induced ARDS and associated coagulopathy may be caused by a direct endothelial infection by the virus in the lungs (Matthay et al., 2019). Another study on a few post-mortem biopsies has, however, illustrated that SARS-CoV-2 nucleocapsid protein immunopositivity is not observed in the mECs and is present only in lung pneumocytes and ciliated epithelial cells (Schaefer et al., 2020). Interestingly, in this study, five patients also exhibit blood clots in the pulmonary vasculature. In absence of a direct pulmonary endothelial involvement and viral infection, this may be explained as diffuse pulmonary intravascular coagulopathy, which is distinct from sepsis-induced disseminated intravascular coagulation (Marchandot et al., 2020; McGonagle et al., 2020). However, an absence of viral positivity in the mECs in this study can also be attributed to technical limitations. Further studies and sensitive imaging techniques are needed to delineate if SARS$\mathrm{CoV} 2$ causes a direct endothelial injury as seen in sepsis-induced ARDS or a direct epithelial injury as in typical ARDS. Both these conditions have different pathological hallmarks and hence can be dissected. A direct endothelial injury can be characterized by increased levels of Angiopoetin-2, von Willebrand factor (vWF), Soluble thrombomodulin, Interleukin 8, Soluble ICAM1 indicating massive endothelial stimulation and damage, while direct epithelial injury can be identified by high plasma levels of surfactant protein-D and receptor for advanced glycation end products (Hendrickson and Matthay, 2018). 


\section{ENTRY OF COVID-19 VIA PULMONARY ENDOTHELIAL CELLS}

In case of direct injury to mEC, SARS-CoV-2 should enter the lungs via the mECs. Angiotensin-converting enzyme 2 (ACE2), the type I integral transmembrane protein, a functional receptor for SARS-CoV and a potential receptor for SARS-CoV-2 is highly expressed in the $\mathrm{mEC}$, along with the lung epithelial cells (Hamming et al., 2004; Hoffmann et al., 2020). Although the contribution of ACE2 in the pathogenesis of COVID19 is not known, yet it has been delineated that SARS-CoV infection downregulates ACE2 and worsens lung injury that is reversed by treatment with Angiotensin receptor blockermediated upregulation of ACE2 (Imai et al., 2005). This study and several others show a protective role of ACE2 in ARDS and lung injury. A recent study has also revealed that the use of human recombinant soluble ACE2 prevented host cell binding to SARSCoV-2, probably by viral binding to proteins in solution rather than those on host cells (Monteil et al., 2020). However, the precise in vivo role of $\mathrm{mEC}$-specific $\mathrm{ACE} 2$ vis-à-vis circulating ACE2 levels in COVID-19 infection and/or severity, especially in context of their vascular effects demand stringent evidencebased studies. Besides ACE2, other receptors such as CD209L and vimentin that have been proposed to serve as putative receptors of SARS viruses are also expressed in mEC (Jeffers et al., 2004; Yu et al., 2016).

Another possibility worth mentioning is that SARS-CoV2 may also be transported to $\mathrm{mEC}$ via air-borne particulate matter with a diameter of 2.5 micrometers (PM2.5) or smaller. These fine air particles can easily reach the smallest of the human airways, cross the alveolar-capillary barrier, deposit on vascular endothelium via specific receptors, modulate vascular permeability and facilitate systemic inflammation, also leading to coagulation (Wang et al., 2017). Recent reports have indeed shown a positive correlation between the increased presence of air pollutants (PM2.5) and COVID-19 spread and lethality (Fattorini and Regoli, 2020). Although the air-borne spread of SARS-CoV-2 via $\mathrm{PM}$ and its direct entry into $\mathrm{mEC}$ remains to be established, it would be interesting to unravel molecular mechanisms if and how SARS-CoV-2 survive and thrive in the mEC.

\section{COVID-19 AND SEPSIS}

COVID-19 infection also seems to mount an attack and exacerbate endothelial damage in other vascular beds (Sardu et al., 2020a). Active SARS-CoV-2 replication in human capillary organoids that closely resemble human capillaries has been demonstrated, suggestive of the fact that the virus could directly infect ACE2-positive blood vessel cells (Monteil et al., 2020). Presence of viral elements within the endothelial cells and diffuse endothelial inflammation has been documented in post-mortem biopsies of lung, heart, kidney, skin and liver (Colmenero et al., 2020; Varga et al., 2020). These studies suggest that a direct SARSCoV-2 infection facilitates endothelial injury in other vascular beds besides the lungs. However, since these are post-mortem biopsies of patients with respiratory failure, it is probable that endothelial damage at this phase is because of an overwhelmed host inflammatory response, rather than viral replication and increased viral loads in the endothelial cells.

A high mortality rate and poor clinical outcomes due to COVID-19 infections in aged subjects and patients with comorbid conditions including diabetes, obesity and hypertension may also be because of an underlying endothelial dysfunction (Yang J. et al., 2020). Indeed, certain features of endothelial dysfunction such as altered permeability, imbalance between vasoconstrictors and vasodilators, markers of procoagulation that are well known to be present in all the above conditions, would serve as key indicators for identifying those subjects who are at a higher risk of developing severe form of the disease. Large-vessel stroke has been described in young patients of COVID-19 with a mean stroke scale of 17 indicating a large area of ischemia. All of them had to be given clot retrieval therapy, anticoagulation and antiplatelets (Oxley et al., 2020). Three patients in this study had diabetes indicating that an underlying endothelial damage might be one of the key reasons of SARS-CoV-2-induced stroke in these patients. Stroke and thrombotic events in brain could also be, however, ascribed to viral infection-induced thrombophilia. The nucleocapsid and spike proteins of the SARS-CoV-2 have been speculated to contribute to a pro-thrombotic state due to their modulation of clotting pathways in the lungs via dysregulation of ACE2 (McGonagle et al., 2020).

The organotropism of SARS-CoV-2 beyond the respiratory tract has been seen in autopsy studies. Besides lungs, viral loads and extensive inflammation have been spotted in the kidneys, liver, heart and brain implicating direct viral tissue damage (Puelles et al., 2020). Given the dissemination of the virus to other organs and presence of MODS in some patients, Li et al. (2020) has conceived the term "viral sepsis" for severe COVID19 infections. Although systemic inflammation may also occur in the wake of an exuberant host cytokine response, given the presence of viral elements in extrapulmonary tissues, it is reasonable to hypothesize that SARS-CoV-2 infection might be spreading through the blood cells and the endothelial route may be one important factor facilitating this viral spread via blood. However, this hypothesis needs further investigations as studies have reported less or even negligible amount of viral RNAemia in infected patients (Huang et al., 2020; Wölfel et al., 2020). More advanced and sensitive diagnostic techniques and the culture of SARS-CoV-2 in blood cells would be needed to confirm the hematogenous spread of viral infection. Here, it is also to be noted that most of the severe COVID-19 patients with ARDS develop bacterial coinfections in the hospitals, thus complicating the true clinical picture (Zhou et al., 2020). It is thus pertinent to clearly distinguish patients with only SARSCoV2 infections from those having SARS-CoV2 plus secondary bacterial infections. A distinguishing marker could be serum procalcitonin (PCT) levels. Unlike patients with bacterial sepsis, PCT values would remain within the reference range in viral sepsis including severe COVID-19 patients as PCT synthesis is known to be inhibited by interferon-gamma released during viral infections (Lippi and Plebani, 2020). A recent elegant study has identified unique immune signatures in severe COVID-19 
patients, characterized by a high sustained cytokine production of interleukin-6 (IL-6), a pleiotropic cytokine with multiple effects in these patients, distinct from patients with bacterial sepsis. COVID-19 patients also show IL-6-mediated low HLADR expression and lymphopenia (Giamarellos-Bourboulis et al., 2020). Further such large-scale studies would shed light on how COVID-19-mediated sepsis is similar and/or different from bacterial sepsis to avoid overlapping of the two distinct diseases.

\section{PERSPECTIVES}

Directly or indirectly, endothelial cells and particularly mECs are a crucial link between SARS-CoV-2 and host immune responses and thus may serve many roles in determining the disease severity and mortality in COVID-19 (Figure 1). As the clinical, pathological and molecular features of COVID19 patients are unfolding in investigational studies, several researchers are hypothesizing and reviewing a vascular-centric pathogenesis of COVID-19. A summary of such recent reviews and short reports is provided in Table $\mathbf{1}$ (Alvarado-Moreno and Majluf-Cruz, 2020; Amraei and Rahimi, 2020; Cure and Cure, 2020; Froldi and Dorigo, 2020; Guler et al., 2020; Gupta et al., 2020; Gustafson et al., 2020; Mangalmurti et al., 2020; Marchetti, 2020; Mondal et al., 2020; Panfoli, 2020; Pons et al., 2020; Sardu et al., 2020b; Teuwen et al., 2020). Hence, undoubtedly, an assessment of endothelial dysfunction in patients with COVID19 to stratify the patients based on severity holds immense relevance. Circulating biomarkers such as endothelin-1, E- and P-selectins, vWF and soluble adhesion molecules that signify endothelial dysfunction may appear as early biomarkers of viral infection and probable organ dysfunction (Goshua et al., 2020). Pulmonary endothelium has the highest expression of the angiogenic factors like, vascular endothelial growth factor (VEGF) and a dysregulated pulmonary angiogenesis is a well-known mediator of acute lung injury (Wada et al., 2013).

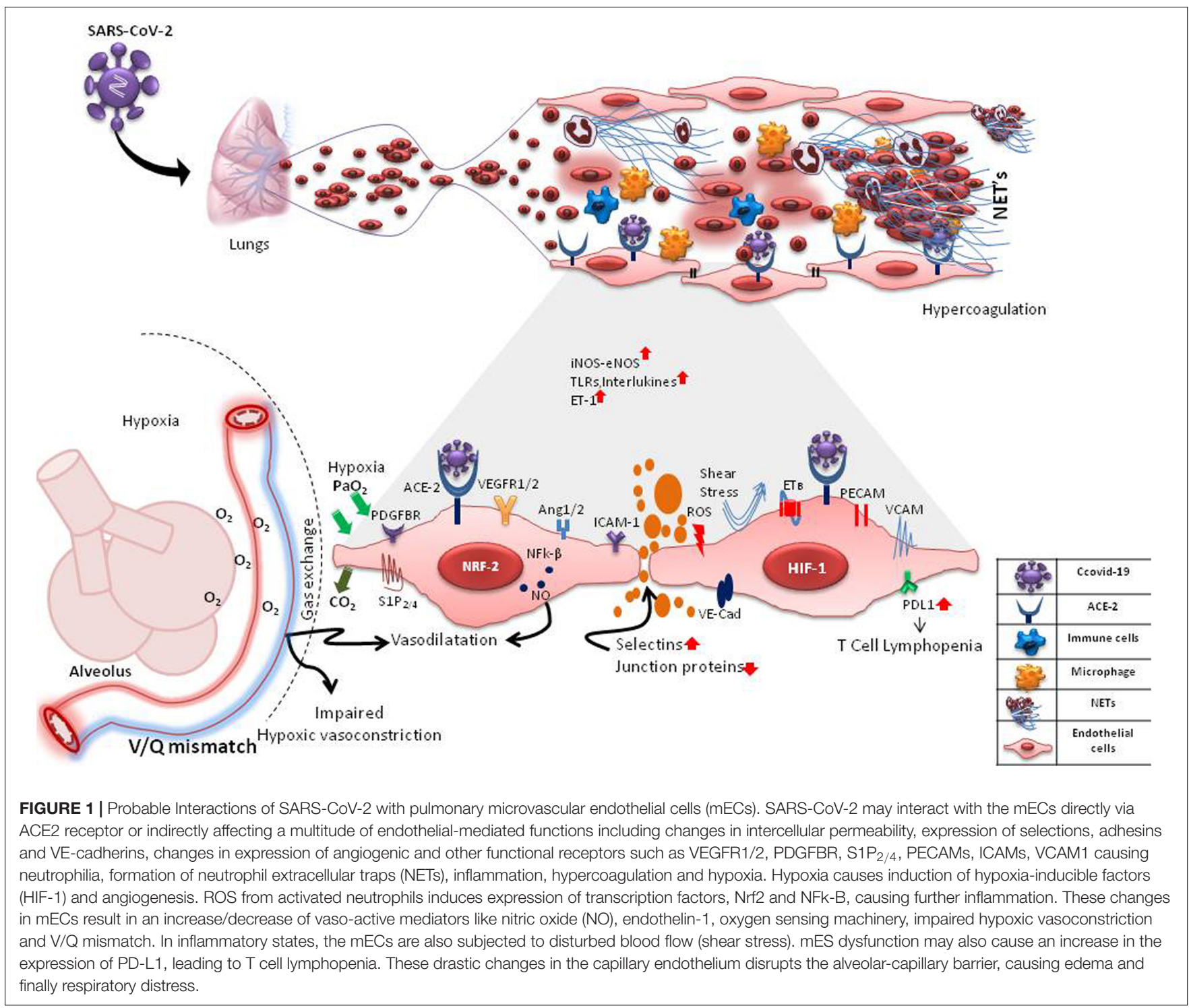


TABLE 1 | Summary of studies hypothesizing an endothelial-specific pathogenesis of COVID-19.

\begin{tabular}{|c|c|c|c|}
\hline S. No & Major views & Type of study & Study (References) \\
\hline 1. & $\begin{array}{l}\text { The endothelium is a key target organ in COVID-19 and a major determinant of disease } \\
\text { severity. }\end{array}$ & Review & (Sardu et al., 2020b) \\
\hline 2. & $\begin{array}{l}\text { Deaths occurring in Mexico at younger age as compared with other countries may be } \\
\text { related to the high frequency of vascular risk factors and the consequent endothelial } \\
\text { dysfunction. }\end{array}$ & Opinion & $\begin{array}{l}\text { Alvarado-Moreno and } \\
\text { Majluf-Cruz, } 2020\end{array}$ \\
\hline 3. & $\begin{array}{l}\text { Key role of endothelial dysfunction during SARS-CoV-2 infection, as a direct target of the } \\
\text { virus and inflammatory cytokines. }\end{array}$ & Review & Pons et al., 2020 \\
\hline 4. & $\begin{array}{l}\text { Binding of virus to ACE2-positive endothelial cells may cause production of ROS, which } \\
\text { cause these cells to acquire a pro-thrombotic and pro-inflammatory phenotype, } \\
\text { predisposing patients to thromboembolic and vasculitic events and to disseminated } \\
\text { intravascular coagulopathy. }\end{array}$ & Short Report & Panfoli, 2020 \\
\hline 5. & $\begin{array}{l}\text { Comparative study between various coronavirus reveals similarities in entry and } \\
\text { pathogenesis of SARS-CoV-2 along with SARS and MERS in various aspects of multi organ } \\
\text { involvement and systematic vasculitis along with similarities in immune-pathogenesis. } \\
\text { The involvement of multiple organs in COVID-19 indicates that endothelial injury leading to } \\
\text { visceral vasculopathy may be the inciting factor in the disease progression. }\end{array}$ & Review & Mondal et al., 2020) \\
\hline 6. & $\begin{array}{l}\text { Vascular-centric pathology of COVID-19-induced ARDS. } \\
\text { Complement pathway activation and ACE2 dysregulation contributing to vascular injury and } \\
\text { thrombosis in COVID-19. }\end{array}$ & Hypothesis and Review & Mangalmurti et al., 2020) \\
\hline 7. & $\begin{array}{l}\text { Passing of SARS-CoV-2 from the respiratory epithelium to the endothelium for viral } \\
\text { dissemination. } \\
\text { Cytokine-driven vascular leak in the lung alveolar-endothelial interface promotes acute lung. }\end{array}$ & Review & Gustafson et al., 2020 \\
\hline 8. & $\begin{array}{l}\text { ACE2 and RAS signaling, as a possible link between the pre-existing endothelial } \\
\text { dysfunction and SARS-CoV-2 induced endothelial injury in COVID-19 associated mortality. } \\
\text { Key roles of endothelial cell-expressed cell adhesion molecules including CD209L/L-SIGN } \\
\text { and CD209/DC-SIGN in SARS-CoV-2 infection. }\end{array}$ & Review & Amraei and Rahimi, 2020 \\
\hline 9. & $\begin{array}{l}\text { Serum Angiotensin II levels are increased with ACE2 blocking by COVID- } 19 \text {. } \\
\text { Angiotensin II stimulation and local stimuli such as } \mathrm{H}^{+} \text {ion and hypoxia activate } \mathrm{Na}^{+} / \mathrm{H}^{+} \\
\text {exchanger (NHE) in both vascular endothelium and platelets. COVID-19 can lead to } \\
\text { thrombosis by causing NHE activation. }\end{array}$ & Letter & Cure and Cure, 2020) \\
\hline 10. & $\begin{array}{l}\text { Apoptotic processes in the ACE2-positive lung microvascular bed endothelium or coronary } \\
\text { endothelium by SARS-CoV-2. } \\
\text { Increased D-dimer may be the result of apoptotic endothelial cell induced coagulopathy. }\end{array}$ & Letter & Guler et al., 2020 \\
\hline 11. & $\begin{array}{l}\text { Endothelial damage mediated by complement activation, inflammation, hypoxia, platelets, } \\
\text { and } A B L \text { tyrosine kinases as relevant cause of death in patients with COVID-19. }\end{array}$ & Review & Marchetti, 2020) \\
\hline 12. & $\begin{array}{l}\text { Endothelial cells play a central role in the pathogenesis of ARDS and multi-organ failure in } \\
\text { patients with COVID-19. }\end{array}$ & Review & Teuwen et al., 2020 \\
\hline 13. & $\begin{array}{l}\text { Increased mortality in young males in Italy linked to the diversity in sex-hormones. } \\
\text { Activation of endothelial estrogen receptors increases nitric oxide and decreases ROS, } \\
\text { protecting the vascular system of females from angiotensin II-mediated vasoconstriction, } \\
\text { inflammation, and ROS production. }\end{array}$ & Hypothesis & Froldi and Dorigo, 2020) \\
\hline 14. & $\begin{array}{l}\text { Extrapulmonary organ-specific pathophysiology and clinical presentation of COVID-19. } \\
\text { Central role of endothelial damage and thrombo-inflammation. }\end{array}$ & Review & Gupta et al., 2020 \\
\hline
\end{tabular}

ROS, reactive oxygen species; ACE2, angiotensin converting enzyme2; ARDS, acute respiratory distress syndrome.

An evaluation of angiogenic factors and their soluble receptors, particularly sVEGFR2 and Angiopoetin-2, might be of prognostic significance in these patients. Circulating endothelial progenitor cells (EPCs) may also be used to assess/predict COVID-19 disease severity and progression in longitudinal studies as altered levels of EPCs have been demonstrated in patients with both acute lung injury and bacterial sepsis (Witzenrath, 2014). Identification of biomarkers and molecular mechanisms underlying COVID-19-induced endothelial injury should lead to new pharmacological targets to ameliorate several processes starting from vascular permeability to neutrophil accumulation, angiogenesis, pro-coagulation to $\mathrm{V} / \dot{\mathrm{Q}}$ mismatching in COVID19 pathogenesis. Meanwhile, a variety of currently used or investigational drugs such as statins, tyrosine kinase inhibitors, atrial natriuretic peptide, $\mathrm{S}_{1} \mathrm{P}_{1}$ agonists that exert endothelial protective or repair effects may be explored for their effects in COVID-19. Dexamethasone, a synthetic corticosteroid and other anti-inflammatory drugs that are already used in many inflammatory diseases including sepsis and ARDS seem to be a ray of hope in mitigating mortality in critically ill patients of COVID-19 (Ledford, 2020). Dexamethasone and other steroids are also known to inhibit endothelial activation and levels of soluble VCAM1 and E-selectins in both in vitro and in vivo models of sepsis (Zielińska et al., 2016). The precise effects of steroid treatment on endothelial function in COVID-19 patients with varying severity thus warrant in-depth investigations. 


\section{CONCLUSION}

To summarize, the pulmonary endothelium seems to be standing at the crossroads of COVID-19, forming the very crux of this baffling disease. Endothelial dysfunction may be both a cause and/or effect of severe COVID-19. It is thus imperative to have further insights into this entity to embark upon newer prognostic markers and effective treatment options for COVID-19 and in fact for viral sepsis in general.

\section{DATA AVAILABILITY STATEMENT}

The original contributions presented in the study are included in the article/supplementary material, further inquiries can be directed to the corresponding author.

\section{REFERENCES}

Ackermann, M., Verleden, S. E., Kuehnel, M., Haverich, A., Welte, T., Laenger, F. et al. (2020). Pulmonary vascular endothelialitis, thrombosis, and angiogenesis in Covid-19. N. Engl. J. Med. 383, 120-128. doi: 10.1056/nejmoa2015432

Aird, W. C. (2007). Phenotypic heterogeneity of the endothelium: II Representative vascular beds. Circul. Res. 100, 174-190. doi: 10.1161/01. res.0000255690.03436.ae

Alvarado-Moreno, J. A., and Majluf-Cruz, A. (2020). COVID-19 and dysfunctional endothelium: the mexican scenario. Arch. Med. Res. doi: 10.1016/j.arcmed.2020. 05.004

Amraei, R., and Rahimi, N. (2020). COVID-19, renin-angiotensin system and endothelial dysfunction. Cells 9:1652. doi: 10.3390/cells9071652

Colmenero, I., Santonja, C., Alonso-Riaño, M., Noguera-Morel, L., HernándezMartín, A., Andina, D., et al. (2020). SARS-CoV-2 endothelial infection causes COVID-19 chilblains: histopathological, immunohistochemical and ultraestructural study of 7 paediatric cases. Br. J. Dermatol. . doi: 10.1111/bjd.19327

Cure, E., and Cure, M. C. (2020). COVID-19 May predispose to thrombosis by affecting both vascular endothelium and platelets. Clin. Appl. Thromb. Hemost. 26:1076029620933945

Ding, Y., Wang, H., Shen, H., Li, Z., Geng, J., Han, H., et al. (2003). The clinical pathology of severe acute respiratory syndrome (SARS): a report from China. J. Pathol. 200, 282-289.

Fattorini, D., Regoli, F. (2020). Role of the chronic air pollution levels in the Covid19 outbreak risk in Italy. Environ. Pollut. 264:114732. doi: 10.1016/j.envpol. 2020.114732

Fox, S. E., Akmatbekov, A., Harbert, J. L., Li, G., Brown, J. Q., and Vander Heide, R. S. (2020). Pulmonary and cardiac pathology in Covid-19: the first autopsy series from new orleans. MedRxiv [Preprint] doi: 10.1101/2020.04.06.200 50575

Froldi, G., and Dorigo, P. (2020). Endothelial dysfunction in Coronavirus disease 2019 (COVID-19): gender and age influences. Med. Hypotheses 144:110015. doi: 10.1016/j.mehy.2020.110015

Galley, H. F., and Webster, N. R. (2004). Physiology of the endothelium. Br. J. Anaesth. 93, 105-113.

Gattinoni, L., Chiumello, D., Caironi, P., Busana, M., Romitti, F., Brazzi, L., et al. (2020). COVID-19 pneumonia: different respiratory treatments for different phenotypes?. Intensive care Med. 46, 1099-1102. doi: 10.1007/s00134-02006033-2

Giamarellos-Bourboulis, E. J., Netea, M. G., Rovina, N., Akinosoglou, K., Antoniadou, A., Antonakos, N., et al. (2020). Complex immune dysregulation in COVID-19 patients with severe respiratory failure. Cell Host Microbe 27, 992.e3-1000.e3.

Giardini, V., Carrer, A., Casati, M., Contro, E., Vergani, P., and GambacortiPasserini, C. (2020). Increased sFLT1/PIGF ratio in COVID-19: a novel link to Angiotensin II-mediated endothelial dysfunction. Am. J. Hematol. 95, E188E191.

\section{AUTHOR CONTRIBUTIONS}

SK developed these perspectives. SK and DT together drafted the manuscript. AY provided support in conceiving and designing the figure under the supervision from DT. SK finalized the manuscript. All authors contributed to the article and approved the submitted version.

\section{ACKNOWLEDGMENTS}

The authors would like to thank Dr. Atampreet Singh (Department of Neurology, Fortis Hospital, Noida, India) for his valuable inputs and discussions while writing of this manuscript.

Goshua, G., Pine, A. B., Meizlish, M. L., Chang, C. H., Zhang, H., Bahel, P., et al. (2020). Endotheliopathy in COVID-19-associated coagulopathy: evidence from a single-centre, cross-sectional study. Lancet Haematol. 7, E575-E582. doi: 10.1016/S2352-3026(20)30216-7

Grimmer, B., and Kuebler, W. M. (2017). The endothelium in hypoxic pulmonary vasoconstriction. J. Appl. Physiol. 123, 1635-1646.

Guler, N., Siddiqui, F., and Fareed, J. (2020). Is the reason of increased D-dimer levels in COVID-19 because of ACE-2-induced apoptosis in endothelium? Clin. Appl. Thromb. Hemost. 26:1076029620935526.

Gupta, A., Madhavan, M. V., Sehgal, K., Nair, N., Mahajan, S., Sehrawat, T. S., et al. (2020). Extrapulmonary manifestations of COVID-19. Nat. Med. 26, 1017-1032.

Gustafson, D., Raju, S., Wu, R., Ching, C., Veitch, S., Rathnakumar, K., et al. (2020). Overcoming barriers: the endothelium as a linchpin of coronavirus disease 2019 pathogenesis?. Arterioscl. Thromb. Vasc. Biol. 40:ATVBAHA12014558.

Hamming, I., Timens, W., Bulthuis, M. L. C., Lely, A. T., Navis, G. J., van Goor, H., et al. (2004). Tissue distribution of ACE2 protein, the functional receptor for SARS coronavirus. A first step in understanding SARS pathogenesis. J. Pathol. 203, 631-637. doi: 10.1002/path.1570

Hendrickson, C. M., and Matthay, M. A. (2018). Endothelial biomarkers in human sepsis: pathogenesis and prognosis for ARDS. Pulm. Circ. 8:2045894018769876.

Hoffmann, M., Kleine-Weber, H., Schroeder, S., Krüger, N., Herrler, T., Erichsen, S., et al. (2020). SARS-CoV-2 cell entry depends on ACE2 and TMPRSS2 and is blocked by a clinically proven protease inhibitor. Cell 181, 271-280.

Huang, C., Wang, Y., Li, X., Ren, L., Zhao, J., Hu, Y., et al. (2020). Clinical features of patients infected with 2019 novel coronavirus in Wuhan. China Lancet 395 , 497-506.

Imai, Y., Kuba, K., Rao, S., Huan, Y., Guo, F., Guan, B., et al. (2005). Angiotensinconverting enzyme 2 protects from severe acute lung failure. Nature 436, 112-116. doi: 10.1038/nature03712

Jeffers, S. A., Tusell, S. M., Gillim-Ross, L., Hemmila, E. M., Achenbach, J. E., Babcock, G. J., et al. (2004). CD209L (L-SIGN) is a receptor for severe acute respiratory syndrome coronavirus. Proc. Natl. Acad. Sci. U.S.A. 101, 15748 15753. doi: 10.1073/pnas.0403812101

Klok, F. A., Kruip, M. J. H. A., Van der Meer, N. J. M., Arbous, M. S., Gommers, D. A. M. P. J., Kant, K. M., et al. (2020). Confirmation of the high cumulative incidence of thrombotic complications in critically ill ICU patients with COVID-19: An updated analysis. Thromb. Res. 191, 148-150. doi: 10.1016/j. thromres.2020.04.041

Ledford, H. (2020). Coronavirus breakthrough: dexamethasone is first drug shown to save lives. Nature 582, 469-469. doi: 10.1038/d41586-020-01824-5

Li, H., Liu, L., Zhang, D., Xu, J., Dai, H., Tang, N., et al. (2020). SARS-CoV-2 and viral sepsis: observations and hypotheses. Lancet 395, 1517-1520. doi 10.1016/s0140-6736(20)30920-x

Lippi, G., and Plebani, M. (2020). Procalcitonin in patients with severe coronavirus disease 2019 (COVID-19): A meta-analysis. Clin. Chim. Acta 505, 190-191. doi: 10.1016/j.cca.2020.03.004 
Liu, Y., Du, X., Chen, J., Jin, Y., Peng, L., Wang, H. H., et al. (2020). Neutrophilto-lymphocyte ratio as an independent risk factor for mortality in hospitalized patients with COVID-19. J. Infect. 81, e6-e12. doi: 10.1016/j.jinf.2020. 04.002

Mangalmurti, N. S., Reilly, J. P., Cines, D. B., Hunter, C. A., Meyer, N. J., and Vaughan, A. E. (2020). COVID-ARDS clarified: a vascular endotype?. Am. J. Respir. Crit. Care Med. Online ahead of print.

Marchandot, B., Sattler, L., Jesel, L., Matsushita, K., Schini-Kerth, V., Grunebaum, L., et al. (2020). COVID-19 related coagulopathy: a distinct entity? J. Clin. Med. 9:1651. doi: 10.3390/jcm9061651

Marchetti, M. (2020). COVID-19-driven endothelial damage: complement, HIF-1, and ABL2 are potential pathways of damage and targets for cure. Ann. Hematol. 99, 1701-1707. doi: 10.1007/s00277-020-04138-8

Matthay, M. A., Zemans, R. L., Zimmerman, G. A., Arabi, Y. M., Beitler, J. R., Mercat, A., et al. (2019). Acute respiratory distress syndrome. Nat. Rev. Dis. Primers 5:18.

McGonagle, D., O’Donnell, J. S., Sharif, K., Emery, P., and Bridgewood, C. (2020). Immune mechanisms of pulmonary intravascular coagulopathy in COVID19 pneumonia. Lancet Rheumatol. 2, e437-e445. doi: 10.1016/s2665-9913(20) 30121- 1

Millar, F. R., Summers, C., Griffiths, M. J., Toshner, M. R., and Proudfoot, A. G. (2016). The pulmonary endothelium in acute respiratory distress syndrome: insights and therapeutic opportunities. Thorax 71, 462-473. doi: 10.1136/ thoraxjnl-2015-207461

Mondal, R., Lahiri, D., Deb, S., Bandyopadhyay, D., Shome, G., Sarkar, S., et al. (2020). COVID-19: Are we dealing with a multisystem vasculopathy in disguise of a viral infection?. J. Thromb. Thrombolysis 5, 1-13.

Monteil, V., Kwon, H., Prado, P., Hagelkrüys, A., Wimmer, R. A., Stahl, M., et al. (2020). Inhibition of SARS-CoV-2 infections in engineered human tissues using clinical-grade soluble human ACE2. Cell 181, 905.e7-913.e7.

Narasaraju, T., Yang, E., Samy, R. P., Ng, H. H., Poh, W. P., Liew, A. A., et al. (2011). Excessive neutrophils and neutrophil extracellular traps contribute to acute lung injury of influenza pneumonitis. Am. J. Pathol. 179, 199-110.

Oxley, T. J., Mocco, J., Majidi, S., Kellner, C. P., Shoirah, H., Singh, I. P., et al. (2020). Large-vessel stroke as a presenting feature of Covid-19 in the young. N. Eng. J. Med. 382:e60. doi: 10.1056/nejmc2009787

Panfoli, I. (2020). Potential role of endothelial cell surface ectopic redox complexes in COVID-19 disease pathogenesis. Clin. Med. doi: 10.7861/clinmed.2020-0252

Pons, S., Fodil, S., Azoulay, E., and Zafrani, L. (2020). The vascular endothelium: the cornerstone of organ dysfunction in severe SARS-CoV-2 infection. Crit. Care 24, 1-8.

Puelles, V. G., Lütgehetmann, M., Lindenmeyer, M. T., Sperhake, J. P., Wong, M. N., Allweiss, L., et al. (2020). Multiorgan and renal tropism of SARS-CoV-2. N. Eng. J. Med. 13:NEJMc2011400.

Ranucci, M., Ballotta, A., Di Dedda, U., Bayshnikova, E., Dei Poli, M., Resta, M., et al. (2020). The procoagulant pattern of patients with COVID-19 acute respiratory distress syndrome. J Thromb. Haemosta. 18, 1747-1751. doi: 10. $1111 /$ jth.14854

Sardu, C., Gambardella, J., Morelli, M. B., Wang, X., Marfella, R., Santulli, G., et al. (2020a). Hypertension, thrombosis, kidney failure, and diabetes: is COVID19 an endothelial disease? a comprehensive evaluation of clinical and basic evidence. J. Clin. Med. 9:1417. doi: 10.3390/jcm9051417

Sardu, C., Gambardella, J., Morelli, M. B., Wang, X., Marfella, R., and Santulli, G. (2020b). Is COVID-19 an endothelial disease? Clin. Basic Evid. 2020:2020040204.
Schaefer, I. M., Padera, R. F., Solomon, I. H., Kanjilal, S., Hammer, M. M., Hornick, J. L., et al. (2020). In situ detection of SARS-CoV-2 in lungs and airways of patients with COVID-19. Mod. Pathol. Online ahead of print.

Sørensen, O. E., and Borregaard, N. (2016). Neutrophil extracellular traps-the dark side of neutrophils. J. Clin. Invest. 126, 1612-1620. doi: 10.1172/jci84538

Teuwen, L. A., Geldhof, V., Pasut, A., and Carmeliet, P. (2020). COVID-19: the vasculature unleashed. Nat Rev. Immunol. 20, 389-391. doi: 10.1038/s41577020-0343-0

Varga, Z., Flammer, A. J., Steiger, P., Haberecker, M., Andermatt, R., Zinkernagel, A. S., et al. (2020). Endothelial cell infection and endothelitis in COVID-19. Lancet 395, 1417-1418.

Wada, T., Jesmin, S., Gando, S., Yanagida, Y., Mizugaki, A., Sultana, S. N., et al. (2013). The role of angiogenic factors and their soluble receptors in acute lung injury (ALI)/acute respiratory distress syndrome (ARDS) associated with critical illness. J. Inflamm. 10:6. doi: 10.1186/1476-9255-10-6

Wang, T., Shimizu, Y., Wu, X., Kelly, G. T., Xu, X., Wang, L., et al. (2017). Particulate matter disrupts human lung endothelial cell barrier integrity via Rho-dependent pathways. Pulm. Circ. 7, 617-623. doi: 10.1086/689906

Witzenrath, M. (2014). Endothelial progenitor cells for acute respiratory distress syndrome treatment: support your local sheriff! Am. J. Respir. Crit. Care Med. 189, 1452-1455. doi: 10.1164/rccm.201405-0827ed

Wölfel, R., Corman, V. M., Guggemos, W., Seilmaier, M., Zange, S., Müller, M. A., et al. (2020). Virological assessment of hospitalized patients with COVID-2019. Nature 581, 465-469. doi: 10.1038/s41586-020-2196-X

Yang, F., Shi, S., Zhu, J., Shi, J., Dai, K., and Chen, X. (2020). Analysis of 92 deceased patients with COVID-19. J. Med. Virol. 15:10.1002/jmv.25891. doi: 10.1002/jmv.25891

Yang, J., Zheng, Y., Gou, X., Pu, K., Chen, Z., Guo, Q., et al. (2020). Prevalence of comorbidities in the novel Wuhan coronavirus (COVID-19) infection: a systematic review and meta-analysis. Int J. Infect. Dis. 94, 91-95.

Yang, X., Yu, Y., Xu, J., Shu, H., Liu, H., Wu, Y., et al. (2020). Clinical course and outcomes of critically ill patients with SARS-CoV-2 pneumonia in Wuhan, China: a single-centered, retrospective, observational study. Lancet Respir. Med. 8, 475-481. doi: 10.1016/s2213-2600(20)30079-5

Yu, Y. T. C., Chien, S. C., Chen, I. Y., Lai, C. T., Tsay, Y. G., Chang, S. C., et al. (2016). Surface vimentin is critical for the cell entry of SARS-CoV. J. Biomed. Sci. 23, 1-10.

Zhou, P., Liu, Z., Chen, Y., Xiao, Y., Huang, X., and Fan, X. G. (2020). Bacterial and fungal infections in COVID-19 patients: a matter of concern. Infect. Control Hosp. Epidemiol. 22, 1-2. doi: 10.1017/ice.2020.156

Zielińska, K. A., Van Moortel, L., Opdenakker, G., De Bosscher, K., and Van den Steen, P. E. (2016). Endothelial response to glucocorticoids in inflammatory diseases. Front. Immunol. 7:592. doi: 10.3389/fimmu.2016.00592

Zuo, Y., Yalavarthi, S., Shi, H., Gockman, K., Zuo, M., Madison, J. A., et al. (2020). Neutrophil extracellular traps in COVID-19. JCI Insight 5:138999.

Conflict of Interest: The authors declare that the research was conducted in the absence of any commercial or financial relationships that could be construed as a potential conflict of interest.

Copyright (C) 2020 Kaur, Tripathi and Yadav. This is an open-access article distributed under the terms of the Creative Commons Attribution License (CC BY). The use, distribution or reproduction in other forums is permitted, provided the original author(s) and the copyright owner(s) are credited and that the original publication in this journal is cited, in accordance with accepted academic practice. No use, distribution or reproduction is permitted which does not comply with these terms. 